Heitor Megale

Sílvio de Almeida Toledo Neto

Phablo Roberto Marchis Fachin

\title{
POR RUMOS DA AGULHA
}

DOCUMENTOS DO OURO DO SÉCULO XVIII

\section{Série Diachronica}

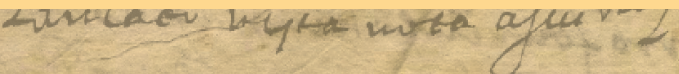

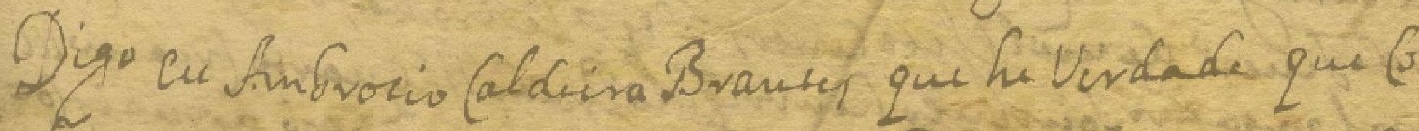

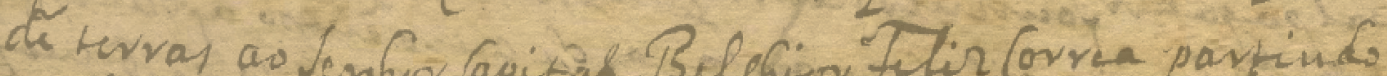

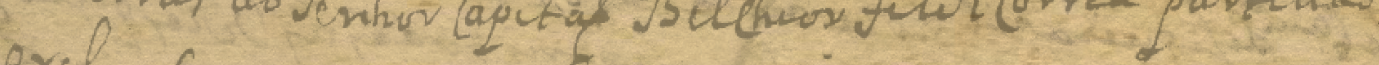

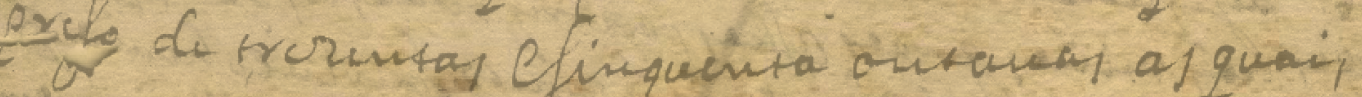

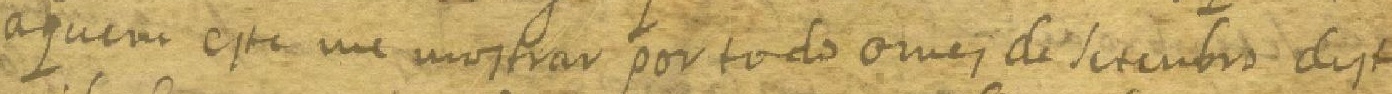

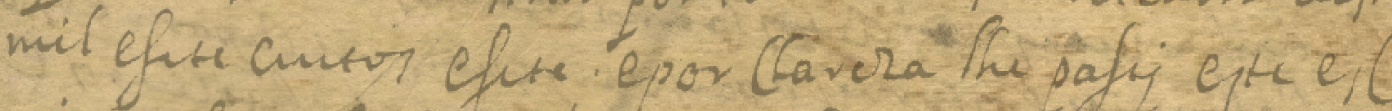

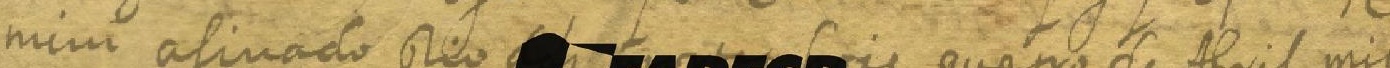
l 7 . 0 .

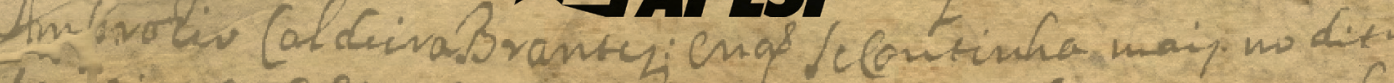
fino clumtar of wh hupors at ecitora $\Rightarrow$ cubo

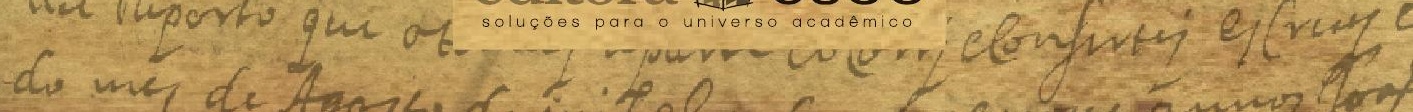





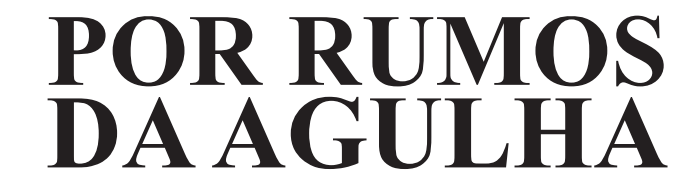

DOCUMENTOS DO OURO DO SÉCULO XVIII 


\section{Série Diachronica 7}

Coordenação da Série Diachronica Sílvio de Almeida Toledo Neto Phablo Roberto Marchis Fachin

Volume 1: Carta de Caminha

CAMBRAIA, César Nardelli, CUNHA, Antônio Geraldo da, MEGALE, Heitor

Volume 2: $\mathrm{E}$ os preços eram commodos BERLINCK, Rosane de Andrade GUEDES, Marymarcia

Volume 3: Cartas Baianas Setecentistas LOBO, Tânia (org.) FERREIRA, Permínio Souza GONÇALVES, Uilton OLIVEIRA, Klebson

Volume 4: Por minha Letra e Sinal MEGALE, Heitor TOLEDO NETO, Sílvio de Almeida

Volume 5: Descaminhos e dificuldades: leitura de Manuscritos do século XVIII FACHIN, Phablo Roberto Marchis

Volume 6: Caminhando mato dentro MEGALE, Heitor TOLEDO NETO, Sílvio de Almeida FACHIN, Phablo Roberto Marchis 


\author{
Heitor Megale
}

Sílvio de Almeida Toledo Neto

Phablo Roberto Marchis Fachin

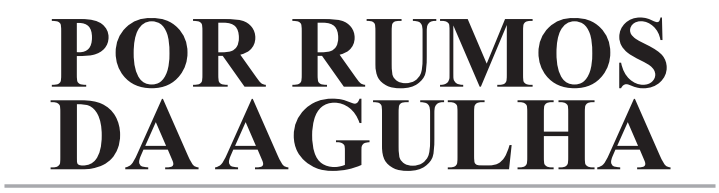

DOCUMENTOS DO OURO DO SÉCULO XVIII

Edição dos manuscritos por Andrea Hitos Ferreira

Cláudia Damião Lopes de Almeida Silveira

Elisabete Massami Nishi

Elizângela Nivardo Dias

Heitor Megale

Keila Makarovsky Galvão

Lia Carolina Prado Alves Mariotto

Maria Célia Lima-Hernandes

Paula Held Lombardi Araujo

Phablo Roberto Marchis Fachin

Renata Ferreira Costa

Renata Ferreira Munhoz

Sílvio de Almeida Toledo Neto

Vanessa Martins do Monte

\title{
editora 1 cubo
}

São Carlos, SP

2015 


\section{Copyrigth (C) 2012 by}

Heitor Megale

Sílvio de Almeida Toledo Neto

Phablo Roberto Marchis Fachin

Revisão de Texto:

Amanda Valeira de Oliveira Monteiro - Ana Claudia de Ataide Almeida Mota

Ana Claudia Zatorre dos Santos - Elizangela Nivardo Dias

Heitor Megale - Maria Fernanda Brito Resende - Phablo Roberto Marchis Fachin

Renata Ferreira Munhoz - Renata Ferreira Costa - Sílvio de Almeida Toledo Neto

Vanessa Martins do Monte

Dados Internacionais de Catalogação na Publicação (CIP)

(Câmara Brasileira do Livro, SP, Brasil)

Por rumos da agulha : documentos do ouro do Século XVIII /

Heitor Megale, Sílvio de Almeida Toledo Neto, Phablo Roberto

Marchis Fachin, (org.) . -- São Carlos, SP : Editora Cubo,

2015. -- (Série diachronica ; v. 7 / coordenadores Heitor

Megale. [et. al.])

ISBN 978-85-60064-64-9

1. Brasil - História - Ciclo do ouro 2. Filologia

3. Manuscritos - Brasil 4. Paleografia 5. Português - Brasil -

História 6. Português - Transcrição 7. Português escrito -

História I. Megale, Heitor. II. Toledo Neto, Sílvio de Almeida.

III. Fachin, Phablo Roberto Marchis. IV. Série.

Índices para catálogo sistemático:

1. Língua portuguesa : Português escrito : Brasil : História :

Século 18 : Linguística aplicada 469.800981

Apoio

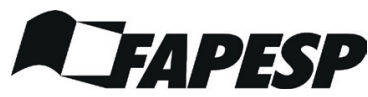




\section{CAPÍTULO II \\ Descrição de documentos}





\section{Identificação e definição dos documentos editados}

Neste capítulo, identificamos e definimos todas as espécies documentais editadas neste volume, segundo os critérios estabelecidos pela Diplomática, ciência que tem como objeto a estrutura formal do documento. ${ }^{1}$ As fontes consultadas são principalmente o glossário do catálogo 1 dos Documentos manuscritos avulsos da Capitania de São Paulo (2000) e Bellotto (2002), os quais seguimos de perto.

Para que bem se compreendam as definições que se seguem, explicamos antes os principais termos técnicos utilizados. Considera-se documento diplomático o registro legitimado de ato administrativo ou jurídico, resultante de fato administrativo ou jurídico. Quanto às categorias documentais, os documentos públicos e notariais podem ser dispositivos, testemunhais e informativos. Os documentos dispositivos podem conter manifestações de vontade de autoridades supremas, obrigatórias para os subordinados; acordos de vontade entre duas ou mais partes; ou a determinação da execução de atos normativos em âmbitos de jurisdição mais restritos. Os documentos testemunhais podem trazer registros oficiais sobre fatos ou ocorrências, ou comprová-los. Os documentos informativos esclarecem questões contidas em outros documentos, para fundamentar uma resolução. Quanto à circulação, os documentos podem ser ascendentes, que sobem dos súditos a instâncias superiores; descendentes, os que descem de autoridades superiores; e horizontais, quando transmitem-se entre autoridades ou pessoas do mesmo nível.

Apresentamos a lista das espécies documentais transcritas, com uma breve definição que contempla as principais características diplomáticas dos documentos estudados.

AUTO: Documento diplomático testemunhal de assentamento, horizontal.

Relato pormenorizado de um acontecimento com a finalidade, em geral, de conduzir um processo a uma decisão ou um infrator a uma sanção.

BILHETE: Documento não-diplomático, descendente ou horizontal, enunciativo, informativo. Em geral de Secretário do Conselho

1 Bellotto (2002: 19) explica o objeto da Diplomática como "a configuração interna do documento, o estudo jurídico de suas partes e dos seus caracteres para atingir sua autenticidade”. 
transmitindo uma concessão real ou solicitando alguma informação necessária à tramitação de algum processo.

CARTA: Documento não-diplomático, de desenho mais ou menos oficializado, ascendente, descendente ou horizontal. Na administração colonial, trata-se de correspondência enviada ao rei por autoridade subalterna ou súdito, diferindo-se dos requerimentos ou petições por não possuir caráter peditório. Assim, quaisquer assuntos que se quisesse expor ao rei eram retratados por meio de carta. Pode tratar, ainda, de questões de caráter particular, em especial quando for um documento horizontal.

CERTIDÃO: Documento diplomático testemunhal comprobatório, horizontal. Documento emanado de funcionário de fé pública mediante o qual se transcreve algo já registrado em documento de assentamento.

CERTIFICADO: Documento diplomático testemunhal comprobatório, descendente, notarial ou não. Declaração que garante a veracidade de um fato ou de um estado de coisas.

CONSULTA: Documento não-diplomático, informativo opinativo, enunciativo, ascendente. Ato pelo qual uma instituição ou indivíduo, em cumprimento de um preceito genérico ou específico da autoridade máxima, o rei, presta assessoria em assunto determinado. $\mathrm{Na}$ administração colonial esse era o tipo de documento utilizado, em geral, pelo Conselho ou por Juntas cujo objetivo fosse assessorar o rei em algum assunto específico. É, portanto, o principal documento-atribuição do Conselho Ultramarino. Na atualidade, pode ser considerado o mesmo que parecer.

ESCRITURA: Documento diplomático, testemunhal de assentamento, notarial. Registro autêntico de um contrato ou de uma transação feito por um oficial notarial.

FÉ DE OFÍCIO: Documento diplomático de assentamento que se configura por registro em estabelecimento notarial. Documento passado em tabelião que serve para atestar serviços prestados pelo interessado.

INSTRUÇÃO: Documento diplomático normativo de correspondência, descendente. Documento de uma autoridade dirigido a um subordinado em que dá ordens gerais, muitas delas a virem a ser detalhadas por meio de outros atos.

INVENTÁRIO: Documento não-diplomático, informativo, horizontal. Lista dos bens de uma pessoa, deixados por óbito, devidamente avaliados, para posterior partilha entre os herdeiros. 
MANDADO: Documento diplomático normativo dispositivo, descendente. Ordem de autoridade judiciária dirigido a determinada pessoa para ser imediatamente cumprida.

OFÍCIO: Documento não-diplomático, mas de desenho mais ou menos oficializado, informativo ascendente ou horizontal. Correspondência entre autoridades subalterna/delegadas entre si ou entre outras autoridades do reino, com exceção do rei.

PARECER: Documento diplomático opinativo ou não-diplomático informativo enunciativo, ascendente ou horizontal. É a opinião técnica sobre um ato. Nos documentos coloniais geralmente aparece no texto de uma consulta, sendo o parecer do Conselho sobre algum assunto específico, servindo de base para a tomada de decisão do rei.

PROCURAÇÃO: Documento diplomático informativo, notarial. Instrumento pelo qual uma pessoa recebe de outras poderes para, em nome delas, praticar atos ou administrar bens.

PROVISÃO: Documento diplomático dispositivo de correspondência, descendente, pelo qual a autoridade competente confere a alguém mercê, que se traduz por um cargo, uma dignidade, um ofício ou autorização para o exercício de sua profissão.

REGIMENTO: Documento diplomático normativo descendente, em que a autoridade manifesta sua vontade, por conjunto de normas disciplinadoras, regedoras, estabelecendo direitos e obrigações e determinando finalidades.

REGISTRO: Documento não-diplomático testemunhal de assentamento. Trata-se de lançamento em livro próprio, sob rubrica e cota, de um documento, de um objeto ou de um bem imóvel devidamente identificado e descrito para efeito de direitos.

RELAÇÃO: Documento não-diplomático, informativo, horizontal. Listagem de nomes de pessoas, de coisas ou fatos, muitas vezes solicitadas, por várias razões e sobre os mais variados objetos, pelas autoridades da metrópole às autoridades delegadas.

REQUERIMENTO: Documento diplomático informativo ascendente. Instrumento que serve para solicitar algo a uma autoridade pública e que, ao contário da petição, está baseado em atos legais ou em jurisprudência.

ROL: Documento não-diplomático informativo. Relação feita com objetivo de transferência, entrega, recolhimento ou empréstimo de objetos.

TESTAMENTO: Documento diplomático testemunhal horizontal, notarial. Ato pelo qual alguém dispõe, para depois da morte, de seus bens ou de parte deles, como expressão de última vontade. 


\section{Relação dos documentos editados}

Segue-se um quadro com a relação dos documentos editados, no qual indica-se o número de ordem do texto, conforme as lições modernizada e semidiplomática, o número da primeira e da última linhas do documento na edição semidiplomática, a espécie documental, a data tópica, as palavras iniciais do texto e a data cronológica.

\section{Quadro 1 - Relação dos documentos editados}

\begin{tabular}{|c|c|c|c|c|c|}
\hline 1 & 0001-0021 & Requerimento & São Paulo & Diz o Marquês de Cascais & $16-03-1701$ \\
\hline 2 & $0022-0428$ & Regimento & Lisboa & Regimento do Superintendente & 19-04-1702 \\
\hline 3 & 0429-0476 & Carta & São Paulo & A Vossa Majestade dei conta & 09-06-1702 \\
\hline 4 & 0477-0705 & Relação & Bahia & Porquanto convém remeter-se & 19-08-1702 \\
\hline 5 & 0706-0724 & Carta & Rio de Janeiro & $\mathrm{Vi}$ a ordem inclusa & 24-02-1703 \\
\hline 6 & $0725-0741$ & Carta & Lisboa & Desembargador José Carvalho Pinto & 07-05-1703 \\
\hline 7 & $0742-0761$ & Carta & Lisboa & Desembargador José Carvalho Pinto & $07-05-1703$ \\
\hline 8 & $0762-0772$ & Instrução & Lisboa & Haverá o escrivão de uma carta & 07-05-1703 \\
\hline 9 & 0773-0786 & Carta & Lisboa & Desembargador José Carvalho Pinto & 07-05-1703 \\
\hline 10 & 0787-0805 & Carta & Lisboa & Desembargador José Carvalho Pinto & 07-05-1703 \\
\hline 11 & 0806-0847 & Declaração & Lisboa & Capítulo 1 Das discórdias & $07-05-1703$ \\
\hline 12 & 0848-0876 & Carta régia & Lisboa & Dom Álvaro da Silveira & 20-09-1703 \\
\hline 13 & 0877-0895 & Carta & Rio de Janeiro & Quando dei conta a Vossa & 24-01-1704 \\
\hline 14 & 0896-0986 & Carta & Santos & Não posso escusar de fazer a Vossa & 28-10-1705 \\
\hline 15 & $0987-1030$ & Certificação & $\begin{array}{l}\text { São João da } \\
\text { Barra }\end{array}$ & Certifico estando de guarnição & 16-12-1705 \\
\hline 16 & $1031-1352$ & Consulta & Lisboa & Vendo-se neste Conselho & $26-10-1706$ \\
\hline 17 & $1353-1387$ & Carta & Taubaté & Meu irmão & 27-03-1707 \\
\hline 18 & $1388-1457$ & Escritura de renúncia & Taubaté & Saibam quantos este público & 26-08-1707 \\
\hline 19 & $1458-1513$ & Escritura de venda & Taubaté & Saibam quantos este público & 14-09-1707 \\
\hline 20 & $1514-1541$ & Crédito & Taubaté & Diz Domingos Jorge Santarém & 07-01-1708 \\
\hline 21 & $1542-1572$ & Crédito & Taubaté & Diz o vigário desta vila, o padre & 13-10-1708 \\
\hline 22 & $1573-1626$ & Escritura de alforria & Taubaté & Saibam quantos este público & 01-02-1709 \\
\hline 23 & $1627-1654$ & Carta & Taubaté & Senhor irmão, terá Vossa Mercê & 21-05-1709 \\
\hline 24 & $1655-1665$ & Provisão & Santos & Por vagar o posto & 13-07-1709 \\
\hline 25 & $1666-1690$ & Crédito & Taubaté & Senhor Capitão Manoel Fernandes & 14-08-1709 \\
\hline 26 & $1691-1729$ & Escritura de dinheiro & Taubaté & Saibam quantos este público & 27-08-1709 \\
\hline 27 & $1730-1793$ & Crédito & Taubaté & Diz Sebastião de Siqueira Gil & 28-08-1709 \\
\hline 28 & $1794-1837$ & Escritura de dívida & Taubaté & Saibam quantos este público & 29-08-1709 \\
\hline 29 & $1838-1855$ & Crédito & Taubaté & Digo eu, Ambrósio Caldeira Brant & 30-08-1709 \\
\hline 30 & 1856-1916 & Crédito & Taubaté & Diz o Padre Vigário Antônio Barreto & 03-10-1709 \\
\hline 31 & 1917-1986 & Crédito & Taubaté & Diz Manoel da Silva Salgado & 04-10-1709 \\
\hline 32 & $1987-2035$ & Escritura de alforria & Taubaté & Saibam quantos este público & 29-10-1709 \\
\hline 33 & 2036-2060 & Carta régia & Lisboa & Antônio de Albuquerque Coelho & 29-11-1709 \\
\hline
\end{tabular}


Capítulo II - Descrição Dos Documentos

\begin{tabular}{|c|c|c|c|c|c|}
\hline 34 & $2061-2242$ & Testamento & Taubaté & Em nome da Santíssima Trindade & 07-12-1709 \\
\hline 35 & $2243-2288$ & Carta & Santos & A fortaleza da planta junta & 1710 \\
\hline 36 & $2289-2343$ & Escritura de alforria & Taubaté & Saibam quantos este público & 08-05-1710 \\
\hline 37 & $2344-2391$ & Escritura de doação & Taubaté & Saibam quantos este publico & $15-09-1710$ \\
\hline 38 & $2392-2434$ & Carta & Guaratinguetá & Oferece-se-me fazer presente & $12-10-1710$ \\
\hline 39 & $2435-2457$ & Certidão & Santos & Ioseph Gomes de Andrade & $16-10-1710$ \\
\hline 40 & $2458-2474$ & Certidão & Santos & Oficiais do Senado da Câmara & $18-10-1710$ \\
\hline 41 & $2475-2484$ & Fé pública & Santos & João da Veiga, público tabelião & $20-10-1710$ \\
\hline 42 & 2485-2517 & Parecer & Santos & A presente planta é uma trincheira & $20-10-1710$ \\
\hline 43 & $2518-2585$ & Carta & Santos & Não se deu logo à execução & $25-10-1710$ \\
\hline 44 & 2586-2599 & Carta & Santos & Vossa Majestade foi servido & $31-10-1710$ \\
\hline 45 & $2600-2614$ & Carta & Minas Gerais & Oferece-se-me fazer presente & $18-11-1710$ \\
\hline 46 & $2615-2666$ & Carta & Santos & Por carta de Vossa Magestade & 20-11-1710 \\
\hline 47 & $2667-2730$ & Procuração & Taubaté & Saibam quantos este público & $29-12-1710$ \\
\hline 48 & $2731-2759$ & Crédito & Taubaté & Diz Domingos Rodriguez do Prado & $30-12-1710$ \\
\hline 49 & $2760-2793$ & Rol de casamento & Taubaté & Diz Francisco Rodriguez Montemor & $18-01-1711$ \\
\hline 50 & $2794-2868$ & Consulta & Lisboa & Por decreto de 23 de janeiro & $11-02-1711$ \\
\hline 51 & 2869-2918 & Escritura de venda & Taubaté & Saibam quantos este público & 23-05-1711 \\
\hline 52 & 2919-2959 & Ofício & Lisboa & Vi a planta da fortaleza & $20-10-1711$ \\
\hline 53 & 2960-3063 & Consulta & Lisboa & Vendo-se neste Conselho & 07-02-1712 \\
\hline 54 & 3064-3084 & Parecer & Lisboa & Pareceu ao Conselho remeter & 09-09-1712 \\
\hline 55 & $3085-3123$ & Traslado de Mandado & Santos & O Desembargador Sebastião Galvão & $01-07-1713$ \\
\hline 56 & $3124-3154$ & Carta & Vila Rica & Quando passei pela Vila de Taubaté & 02-01-1714 \\
\hline 57 & $3155-3174$ & Consulta & Lisboa & O governador e Capitão General & 24-03-1714 \\
\hline 58 & 3175-3209 & Carta patente & $\begin{array}{l}\text { Vila de N. }{ }^{a} \text { S. }^{\text {a }} \\
\text { do Carmo }\end{array}$ & Dom Braz Balthasar & 20-09-1714 \\
\hline 59 & $3210-3292$ & Carta & $\begin{array}{l}\text { Santana do } \\
\text { Panaíba }\end{array}$ & Não podemos por lei & $20-10-1714$ \\
\hline 60 & $3293-3300$ & Carta & Lisboa & Por ordem de Vossa Majestade & $22-10-1714$ \\
\hline 61 & $3301-3332$ & Consulta & Lisboa & Vendo-se neste Conselho & 05-11-1714 \\
\hline 62 & $3333-3371$ & Consulta & Lisboa & Manoel Mosqueira da Rosa & 23-01-1715 \\
\hline 63 & $3372-3390$ & Carta pessoal & Pitangui & Recebi a de Vossa Mercê & $01-07-1715$ \\
\hline 64 & $3391-3482$ & Pedido & Lisboa & Diz Anna Maria Duarte & a10-01-1716 \\
\hline 65 & 3483-3529 & Certificação & $\begin{array}{l}\text { São Luis do } \\
\text { Maranhão }\end{array}$ & Certifico que em 20 de maio & 24-07-1716 \\
\hline 66 & $3530-3558$ & Provisão & $\begin{array}{l}\text { São Luis do } \\
\text { Maranhão }\end{array}$ & Faço saber aos que esta minha & $\ldots-11-1716$ \\
\hline 67 & 3559-3604 & Carta régia & Lisboa & Dom João, por graça de Deus & $08-02-1717$ \\
\hline 68 & $3605-3786$ & Consulta & Lisboa & Ordenando-se ao governador & $19-12-1718$ \\
\hline 69 & $3787-3802$ & Carta & Santos & Por carta de 12 de julho & $20-12-1718$ \\
\hline 70 & $3803-3827$ & Carta & Santos & O Conde General das Minas & 15-03-1719 \\
\hline 71 & $3828-3842$ & Carta & Santos & Achou-se que a contribuição & 08-05-1719 \\
\hline 72 & 3843-3856 & Carta & Santos & Os Padres da Companhia & 12-05-1719 \\
\hline 73 & $3857-3891$ & Carta & Santos & Ao porto desta vila & $16-05-1719$ \\
\hline 74 & $3892-4227$ & Auto de Assentada & Santos & Ano do nascimento de Nosso & $30-05-1719$ \\
\hline 75 & $4228-4243$ & Carta & Santos & Com o auto incluso & 08-06-1719 \\
\hline
\end{tabular}


Capítulo II - Descrição Dos Documentos

\section{EMENTAS DOS DOCUMENTOS EDITADOS}

\section{Documento 01}

Requerimento do Marquês de Cascais solicitando a Sua Majestade alvará para citar o procurador da Fazenda pela dízima dos quintos do ouro que saíram de suas terras.

\section{Documento 02}

Regimento do Superintendente, guarda-mor e mais oficiais das minas do ouro de São Paulo, para boa direção e governo das pessoas que trabalham nas minas, conferindo ao superintendente autoridade para manter a ordem. Instrui a respeito da medição das datas, de sua distribuição, e do seu rendimento. Impede gestões visando a aumento de salários acima do estabelecido neste regimento; exige livro do guarda-mor rubricado pelo superintendente, para lançamento das informações das braças de terra de cada mineiro; manda controlar quantos entrem nas minas, disciplinando a atividade de quem traz gado para vender; traz medidas para impedir o descaminho dos quintos, impõe expulsão de ourives que tenham ouro e proíbe ourives escravo. Quer rigor na arrecadação, orienta a nomeação de tesoureiro dos quintos, outorga autoridade cível e do crime ao superintendente.

Documento 03

O ouvidor geral da vila de São Paulo e capitanias do sul escreve a Sua Majestade para informar o que mais convém à administração da Justiça, sugerindo sejam os réus sentenciados e punidos por devassas tiradas por um juiz de capa e espada, e que os casos comprovados tenham pena de morte.

\section{Documento 04}

Em cumprimento a dispositivos das Ordenações, dá relação do dinheiro gasto com o terço dos paulistas, sob as ordens do mestre de campo, Manoel Álvares de Morais Navarro, entre 1698 e 1702 . Os mandados são listados com o valor e a finalidade para a qual foi gasto. Documento 05

Carta em que se declara exato cumprimento da ordem de não se 
autorizar entrada nas minas a pessoas a quem é proibido, mas queixase de que os castigos aos que entram não conseguem dissuadir a ambição. Sugere seja compartilhada a autoridade do superintendente pelos guardas-mores para expulsão dos invasores e confisco de seus bens.

\section{Documento 06}

Carta do Desembargador José Carvalho Pinto declarando que revoga a exclusão das pessoas que ajudaram a descobrir minas, que impedia de atribuir-lhes datas, determinando se dê cinco braças de repartição a cada um dos sócios, a sua escolha.

\section{Documento 07}

Carta do Desembargador José Carvalho Pinto declarando que altera o disposto nos artigos 9 e 10 do regimento, quanto à impossibilidade de outro interesse além do salário previsto, permitindo ao guardamor, ao tesoureiro e mais oficiais que possam minerar e usar das conveniências que as minas dão de si.

Documento 08

Dispõe sobre a forma dos emolumentos do escrivão e meirinho das datas, em consequência da revogação dos capítulos 9 e 10.

\section{Documento 09}

Carta do Desembargador José Carvalho Pinto autoriza tenham os guardasmores seus guardas substitutos que assistam nas partes mais distantes, com as mesmas conveniências de minerar concedidas ao guarda-mor.

Documento 10

Carta do Desembargador José Carvalho Pinto autorizando atribuição de datas de meia, de modo a se cobrirem os gastos em minerar todos por conta própria, tirando-se do ouro metade para a Fazenda Real, ficando a outra metade para a mineração.

\section{Documento 11}

Declaração que relaciona, à maneira de títulos, os assuntos dos trinta e dois capítulos do Regimento.

\section{Documento 12}

Carta régia dirigida a Dom Álvaro da Silveira dirimindo algumas 
dúvidas em relação a se fazer de novo uma casa para o lavor da moeda com as oficinas necessárias.

\section{Documento 13}

Carta dirigida a Sua Majestade, em que se dá conta da averiguação da prata e das esmeraldas, proposta feita por Antonio Correa da Veiga, por seu procurador Antonio de Oliveira Guimarães. Para cumprimento da diligência, refere o número de quinze índios, sendo ordenado que se buscasse mais nas aldeias das vilas do sul.

\section{Documento 14}

Carta dirigida a Sua Majestade, em que o governador da Praça de Santos, José Monteiro de Mattos, faz queixa contra o juiz por atitudes despóticas de régulo ou soberano em relação a pessoas simples, como um negro, preso e açoitado, bem como por acinte e desrespeito a autoridades. Pede que Sua Majestade mande seja o tal juiz publicamente repreendido.

\section{Documento 15}

Francisco Henriques de Miranda, Capitão de Infantaria, certifica que estando de guarnição na praça de Elvas, recebeu ordem de se incorporar ao de Aronches, seguindo em direção à praça de Alcântara. Trata-se de atitude bélica portuguesa ao tempo da sucessão na Espanha, com o risco de Luís XIV unir a monarquia espanhola à França e, em conseqüência, Portugal e colônias.

\section{Documento 16}

Consulta em que o presidente do Conselho Ultramarino, o Conde Mesquita S. S. Barbosa, escreve a Sua Majestade a respeito de vários assuntos, após exame pelo Conselho de sucessivos arbítrios sobre as minas. A renda das minas foi a matéria mais debatida, em função dos descaminhos dos quintos do ouro. Pronuncia-se contra o desvio de dinheiro na casa da moeda, e reconhece a dificuldade de impedir as irregularidades. Considera que os açúcares e os tabacos seriam as melhores minas do Brasil, porque estáveis e perpétuas, enquanto o ouro, com a corrida excessiva de pessoas para a mineração, acarreta impossibilidade de atender a todas as necessidades. Por outro lado, 
fica o reino desprovido de pessoas para sua defesa, e as povoações no Brasil, sem os moradores ficam infestadas de inimigos da Coroa. Sugere conceder só aos paulistas irem todos os anos com trezentos negros para o trabalho das minas. Propõe o pagamento das sisas de todas as coisas que se vendam, e não acha conveniente a venda do ouro na casa da moeda, por ser um dos grandes instrumentos do descaminho do ouro.

\section{Documento 17}

Carta de Manoel Munhoz Pais para seu irmão e senhor, Domingos Nunes, pedindo paciência por seu atraso em quitar empréstimo, o que pretende fazer em agosto próximo, correndo os juros desde o tempo em que passou o crédito. Pede tmbém não leve a mal, se quitar outra dívida antes dessa, porque prefere envergonhar-se pedindo dilação a um irmão do que a um estranho.

Documento 18

Escritura de doação e renúncia que fazem Maria Portes del Rei, viúva do Capitão Bartolomeu da Cunha Gago, seu filho Bartolomeu da Cunha Gago e a mulher desse, Margarida Bueno da Veiga, moradores em Taubaté, para o Capitão Amador Bueno da Veiga, casado com Marta de Miranda Del Rei, filha mais velha da referida viúva, moradores em São Paulo. Trata-se de doação causa dotis.

\section{Documento 19}

Escritura de venda de um pedaço de terras no bairro de Tremembé, que faz o Capitão Jaques Félix a Francisco Pinto de Macedo, ambos moradores em Taubaté. $\mathrm{O}$ valor da venda foi de dez mil réis, pagamento esse feito com uma espingarda de quatro palmos com seus anéis de prata.

Documento 20

Escritura de Crédito que requereu Domingos Jorge Santarém ao Juiz Ordinário, Capitão João de Toledo e Pisa, para enfrentar as dificuldades que vai encontrar para ir para as minas. Quer seja lançado no livro de notas referido crédito. $\mathrm{O}$ tabelião traslada o crédito de duzentos e setenta mil réis que Baltazar do Rego da Silva deve a Domingos Jorge 
Santarém, e pretende quitar em fevereiro vindouro.

Documento 21

O Padre Antonio Barreto de Lima, vigário desta vila, quer remeter para as minas um crédito para fazer cobrança. Quer que a escritura de crédito seja lançada no livro de notas. Trata-se de crédito de quinhentos mil réis, a razão de oito por cento cada ano, que Manoel da Costa Escobar declara que pagará ao padre, em julho próximo. $\mathrm{Na}$ escritura de crédito foi encontrado um recibo assinado por Lima, em que está dito que recebeu do mesmo padre os juros do dinheiro acima referido.

\section{Documento 22}

Escritura de alforria que faz o Capitão Lourenço Castanho, morador em São Paulo, a Maria, moça parda. Diz que havia sempre recebido bons serviços dela, que lhe havia também entregue seiscentas e cinqüenta oitavas de ouro em pó, razões pelas quais dava-lhe liberdade e alforria

\section{Documento 23}

Carta de Manoel Munhoz Pais a seu irmão, em que declara estar de volta das minas sem um oitava de ouro sequer. Pede paciência até ter como pagar sua dívida. Pede que dê dez patacas ao tio, Capitão João de Siqueira Caldeira, e aquando da visita à mãe leve a espingarda que ficou com o primo, Manuel Gomes, sendo que, na ocasião, fará o pagamento.

Documento 24

Provisão em que o mestre de campo e governador da praça de Santos, José Monteiro de Mattos, nomeia Pedro Macedo para o posto de condestável, vago por promoção de Antônio Rodrigues.

Documento 25

Escrito de Lourenço Velho Cabral, juiz ordinário de Guaratinguetá a Manuel Fernandes Pinto, lançado em nota a pedido do Padre Antonio Bicudo de Siqueira, ordenando diligências para prender a João Ferreira.

Documento 26

Escritura de dinheiro a ganhos que faz Diogo Arias de Aguirre a 
Salvador Moreira de Castilho, no valor de cento e oitenta mil e seiscentos réis, a razão de oito por cento ao ano, obrigados sua pessoa e seus bens de raiz havidos e por haver, tendo como fiador Antonio Arias Correa.

\section{Documento 27}

Escritura de Crédito do capitão Sebastião de Siqueira Gil, que pede seja lançada no livro de notas, com quatro créditos, sendo o primeiro de doze libras de ouro em pó mais trinta e uma oitavas de ouro em pó, um areal e outros variados bens, tudo que lhe ficou devendo Salvador Gil; o segundo, de cento e quarenta e cinco oitavas de ouro procedidas de ouro de empréstimo de milho, que lhe devia Nazário; o terceiro de cento e vinte oito oitavas de ouro em pó, que lhe deve Pedro da Fonseca Magalhães, tendo como fiador e pagador principal Lourenço Henrique do Prado; e o quarto de doze oitavas de ouro em pó, que lhe deve Lourenço Henrique do Prado.

\section{Documento 28}

Escritura de dívida que faz o capitão Francisco de Almeida Gago de bens e dinheiro que deve à fazenda de Domingos Gonçalves. É uma dívida de trezentos e vinte e um mil réis, dos quais cento e quarenta mil e quinhentos pela compra do negro José, e os restantes cento e oitenta mil e quinhentos por outro negro de nome Pedro, ambos arrematados em leilão dos bens de Domingos Gonçalves, forasteiro que se suicidou.

\section{Documento 29}

Escritura de Crédito ao Capitão Sebastião Siqueira Gil, lançada em notas a seu requerimento. É uma dívida de trezentas e cinqüenta oitavas pela compra de duas datas e meia de terras compradas por Ambrósio Caldeira Brant do Capitão Belquior Felix Correa, partindo com o Padre Barreto.

Documento 30

Escritura de Créditos do muito reverendo Vigário da vara, o Padre Antonio Barreto de Lima, sendo o primeiro de quinhentas oitavas de ouro em pó, e o segundo, de duzentas e quarenta, tudo, que lhe deve 
Paulo Duarte Coelho.

\section{Documento 31}

Escritura de seis créditos de Manoel da Silva Salgado, que pede seja lançada no livro de notas, sendo o primeiro de mil quatrocentos e quarenta réis, que lhe deve Domingos da Cunha Prado; o segundo, de dezoito oitavas de ouro em pó, que lhe deve Felipe Cabral; o terceiro, de duzentos e dez mil e quinhentos e oitenta réis, que lhe deve Gaspar Vaz da Cunha; o quarto, setenta e seis mil e oitocentos réis, que lhe deve Luis Cabral do Prado; o quinto, trinta e um mil quatrocentos e sessenta réis, que lhe deve Paulo Duarte Coelho; e o sexto, trezentos e onze mil e quarenta réis, que lhe deve Lourenço Henrique do Prado.

\section{Documento 32}

Escritura de alforria feita por Maria Cardoza, dona viúva, a João, um mameluco, filho de uma negra de sua administração e de um homem branco, atendendo a que, conforme alvará de Sua Majestade, seja dada liberdade a semelhantes mamelucos, dando-se por satisfeita com os quatro mil réis que recebeu das mãos de Gabriel Pimenta de Oliveira, que se diz com certeza ser o pai do dito João.

\section{Documento 33}

Carta régia ordenando seja estabelecida uma avença, pela qual as pessoas que se ocupam das minas pagarão valor certo por dia do ouro que se costuma tirar da parte que mineram.

\section{Documento 34}

Testamento de Mariana de Freitas, que o mandou escrever por José Leitão de Abreu. Declara ser natural de São Paulo, filha legítima de Manuel Fernandes Yegra e de Maria Cubas, ter sido casada com Amaro Gil Cortês, de quem teve onze filhos, ser pobre, morando em casa do genro, João Vaz, não ter dívida alguma e se, de sua terça, sobrar alguma coisa, seja dada à filha, Maria Dias. Segue-se o termo de apresentação e abertura do testamento cerrado com três pingos de lacre de cada banda.

Documento 35

Carta em que Pedro Gomes Chaves avalia a construção da fortaleza 
para a defesa da Praça de Santos. Começa pelo exame o lugar escolhido, reconhece que a despesa não será pouca, e também que a Fazenda Real não conseguiria superar as dificuldades, nem impedir os descaminhos dos recursos. Sugere, então, se aceite que João de Castro a faça a suas expensas, visto que a promete pronta em seis anos.

Documento 36

Escritura de alforria que faz Materiana Cabral a Ana, negra de sua administração, e a seu filho, Pedro, pelos bons serviços que de ambos tem recebido. Estando velha e não querendo deixar que mãe e filho continuem escravos, por não poder pagar-lhes os serviços, dá-lhes plena alforria e liberdade, pelo amor e temor de Deus, sem constrangimento de pessoa alguma.

\section{Documento 37}

Escritura de doação de cem braças de terras em quadra passada por Marta de Miranda Muniz a seu genro, Diogo Dias de Aguirre, em causa dotis, pelo casamento com sua filha Francisca Cardoso.

Documento 38

Carta em que Antônio Albuquerque Coelho de Carvalho recomenda a Sua Majestade considere que João de Castro, que tem cabedal, é brioso e deseja servir a Sua Majestade, deseja fazer a fortaleza para segurança do porto de Santos.

\section{Documento 39}

O escrivão de Alçada e de Sindicatura das capitanias do sul, Ioseph Gomes de Andrade, certifica que encontrou a Vila de Santos sem administração alguma da justiça, devido à suspensão do ouvidor geral da Comarca, Dr. João Saraiva de Carvalho. Também certifica que o mestre de campo e governador desta praça, Manuel Gomes Barbosa, tratou com diligência das fortalezas desta vila.

\section{Documento 40}

Oficiais do Senado da Câmara da vila de Santos certificam o mestre de campo e governador desta praça, Manuel Gomes Barbosa, tomou posse do governo da vila e o está exercendo com pontualidade, zelo e satisfação. 
Documento 41

João da Veiga, público tabelião do judicial e notas, dá fé pública a José Gomes de Andrade, reconhecendo sua firma no documento aqui editado a linhas 2089 a 2108 , vindo nessa última sua assinatura.

\section{Documento 42}

Parecer em que Pedro Gomes Chaves expõe que a planta é uma trincheira que se deve fazer na montanha de Monserrate, com domínio da ilha, de grande parte da costa e da barra. A própria dificuldade de acesso é favorável, pois facilita vencer algum inimigo que tenha conseguido entrar na barra. Declara que o governador atual e o anterior são do mesmo parecer.

Documento 43

Carta de Manuel Gomes Barbosa, governador da praça de Santos, a Sua Majestade, encarecendo a Sua Majestade que a construção da fortaleza seja confiada a João de Castro Oliveira que a executará em seis anos, em condições que se pode atender.

\section{Documento 44}

Carta em que o desembargador sindicante, Antônio da Cunha Souto Maior, em cumprimento a ordem de Sua Majestade, informa que Bento do Amaral Gurgel é culpado da morte do provedor da Fazenda do Rio de Janeiro, Pedro de Souza, segundo devassa que se tirou.

\section{Documento 45}

Carta que escreve Pedro Gomes Chaves a Sua Majestade informando que esteve em Santos, em companhia do governador de São Paulo e Minas, Antônio de Albuquerque Coelho de Carvalho, de quem cumpriu ordem de vistoria dos portos para definir o que seria melhor para sua defesa. Sugere que Sua Majestade avalie as plantas para resolver o que for mais conveniente para o real serviço.

\section{Documento 46}

Manuel Gomes Barbosa se queixa a Sua Majestade de que diversas ordens de Sua Majestade não estão sendo cumpridas, o que provoca prejuízos pessoais a ele, e danos à segurança da praça de Santos, do Rio de Janeiro, e da Vila de São Vicente, estando como que em levante. 


\section{Documento 47}

O Capitão Domingos Rodrigues de Carvalho passa procuração a diversas pessoas em Taubaté, em São Paulo, no Rio de Janeiro e na Bahia para cobrar, receber e arrecadar dívidas, fazendas, dinheiro, ouro, prata, peças escravas e administradas, encomendas, carregações e seus procedidos, com poderes para liquidar, citar devedores, lançar bens de devedores em leilão, dar quitação e substabelecer esses poderes onde for necessário.

\section{Documento 48}

Traslada-se uma Escritura de Crédito de Paulo Preto, a requerimento do síndico do convento de Santa Clara, Domingos Rodrigues do Prado, que declara ter Manuel Adorno feito doação ao convento de um crédito de duzentas oitavas de ouro em pó. Paulo Preto diz que é verdade que deve a Manuel Adorno referidas oitavas, que pagou por ele a João Rodrigues Moreira, as quais lhe pagará em agosto.

Documento 49

Rol de casamento Francisco Rodriguez Montemor, casado com Andresa Félix, filha do Capitão Jaques Félix, pede lançamento em nota com despacho do juiz ordinário do rol de casamento de sua mulher, embora passados tantos anos. Segue a relação dos bens.

\section{Documento 50}

O Conselho Ultramarino examina a reclamação do Bacharel, Sebastião Galvão Rasquinho, e sugere que Sua Majestade, levando em conta seus argumentos de que não é possível sustentar-se na ouvidoria com duzentos mil réis, e outras razões de justiça, sugere seja atendida sua reivindicação.

\section{Documento 51}

Em nome de seu constituinte, Domingos Garcia Velho, que está nas minas, e com procuração da mulher, Catarina Rodrigues Pais, o Capitão Bartolomeu Garcia Velho passa, em Pindamonhangaba, escritura de venda de umas casas de taipa de pilão, cobertas de telha, a Domingos Soares Neves, pela quantia acertada de cento e dez mil réis de dinheiro de contado. 


\section{Documento 52}

Manuel Pimentel, do Conselho Ultramarino, tendo visto a planta da fortaleza que se intenta fazer na barra da praia de Santos, critica a opção pelo método francês, propõe sua substituição pelo lusitano, acha razoável o orçamento de João de Castro de Oliveira e vê vantagem em dispensar-se o depósito de pólvora no outeiro de Monserrate. Termina dizendo que o Conselho resolverá o que for mais acertado.

\section{Documento 53}

O Conselho Ultramarino decide que Manuel Pimentel faça nova planta da fortaleza de Santos e, acatando opinião do governador da vila, Antônio de Albuquerque Coelho de Carvalho considera que se devia abraçar a oferta de João de Castro de Oliveira, atendidas suas condições.

\section{Documento 54 com}

Parecer juntado à planta da fortaleza de Santos, remetido a Sua Majestade pelo Conselho Ultramarino. Seu autor, fez Manuel Pimentel, opina que, para garantir toda a segurança, deve a planta ser examinada por engenheiro, para o desenho que for mais conveniente.

\section{Documento 55}

Traslado de Mandado em que o ouvidor geral de São Paulo, Desembargador Sebastião Galvão Rasquinho, manda aos juízes ordinários de Santos façam citar o desembargador sindicante, Antônio da Cunha Souto Maior, pelo crime de que se tirou devassa. Segue-se despacho do juiz, entendendo não cumprir o mandato, por expressamente contrário às Ordenações vigentes.

O Desembargador Sebastião Galvão

\section{Documento 56}

Conta Braz Bacelar da Silva que, de passagem pela Vila de Taubaté, soube do assassinato de José Ventura de Mendanha, por João Batista e gente e escravos de Antônio Correa. Pronunciados os culpados, intentaram vir à vila com muitos escravos armados para insultar o juiz. Remete a Sua Majestade informações acerca dos desdobramentos do fato. 


\section{Documento 57}

O Conselho Ultramarino relata a Sua Majestade informação de carta do Governador e Capitão Geral de São Paulo e Minas, Dom Braz Balthasar da Silveira, de sua acolhida em São Paulo.

\section{Documento 58}

Dom Braz Balthasar da Silveira, Governador e Capitão Geral de São Paulo e Minas, provê, mediante carta patente, a João Barreiros de Araújo no posto de Coronel de um regimento de cavalaria da ordenança que determina formar nos descobrimentos de Batipoca.

\section{Documento 59}

Os oficiais da Câmara da vila de Santana do Parnaíba escrevem a Sua Majestade para lamentar a desventura de ficarem sujeitos a excessos de graves conseqüências, por viverem tão distantes do reino, como o do sindicante, Antonio da Cunha Souto Maior, a que se seguiu a assuada dos moradores desta vila. Sugere que os presos cumpram degredo nos sertões, em diligências do ouro e da prata, o que propiciaria grandes aumentos à Coroa.

\section{Documento 60}

Carta em que o desembargador declara ter cumprido ordem de Sua Majestade recebendo do ouvidor quinze moedas e uma barra de ouro falsas, e pergunta o que fazer com elas.

\section{Documento 61}

O Conselho Ultramarino pronuncia-se nesta consulta favoravelmente em relação à petição de João da Fonseca Coutinho Souto Maior, irmão de José Bento Mendanha, assassinado em Taubaté, por João Batista e gente e escravos de Antonio Correa, solicita se faça devassa pelo ouvidor do Rio de Janeiro, e sugere abstenha-se o governador de demolir casas, salvo casas fortes que obstruam da justiça.

\section{Documento 62}

Manoel Mosqueira da Rosa pede a Sua Majestade lhe seja dada a mesma ajuda de custo de seu antecessor, quinhentos mil réis. Ao Conselho Ultramarino parece que Sua Majestade haja por bem que se lhe dê ajuda de custo de duzentos mil réis. 


\section{Documento 63}

Garcia Rodrigues Pais Betim escreve de Pitangui a Pedro Taques de Almeida, pedindo que espere por seu pagamento de empréstimo, prometendo satisfazer a tudo com o que espera de suas lavras.

\section{Documento 64}

Anna Maria Duarte dirige-se a Dom João V dizendo que é órfã, solteira, moradora em Lisboa, à Rua da Inquisição. Conta que seu irmão, já falecido, exerceu funções públicas durante quinze anos, conforme atestam os documentos juntados a seu requerimento. Pede que, em consideração aos serviços prestados por seu irmão, seja ela nomeada para a Tesouraria da Obra Pia, com tença de duzentos mil réis.

\section{Documento 65}

Christóvão da Costa Freire informa o provimento de Gervásio Leite Rebelo como Secretário de Estado do Maranhão, em conseqüência de estar de partida Antônio Rodrigues Chaves, para tratamento de saúde. Documento 66

Christóvão da Costa Freire certifica que chegou a São Luís do Maranhão Gervásio Leite Rebelo, provido como Secretário de Estado. Informa a dedicação com que o acompanhou em visitas, e as conseqüências de um entrevero com índios.

\section{Documento 67}

Carta régia em que Sua Majestade ordena ao provedor da fazenda da vila de Santos que siga a causa da passagem do Cubatão, em juízo, por embargo dos padres da Companhia de Jesus, e manda que sentencie com brevidade a faça remeter os autos ao Conselho Ultramarino.

\section{Documento 68}

É assunto desta consulta do Conde de Assumar sobre a fundação de casas das moedas nas minas, com o objetivo de minorar os descaminhos do ouro. Os Conselheiros ponderam que, em qualquer parte que se encontrem, seriam convenientes e necessárias. Reconhecem a impossibilidade de impedir os extravios do ouro não quintado, havendo inconvenientes em se executar o que se mandou perguntar. É lembrado o exemplo de Potosi, onde entre 1543 e 1585 , 
de onze milhões de pesos que se haviam quintado, o que não o foi seria outro tanto.

\section{Documento 69}

Timóteo Correa de Góis queixa-se a Sua Majestade do motim dos soldados, por não lhes pagarem as fardas, tendo ficado impunes e absolvidos, em nome de Sua Majestade.

Documento 70

Timóteo Correa de Góis apresenta a Sua Majestade suas razões para o não cumprimento da ordem de pagar seiscentos mil réis de propina, pela execução em São Paulo do contrato dos dízimos.

Considera-se perdido o navio por falta de condições de navegar. Espera seja Sua Majestade servido mandar que, com esse dinheiro, sejam pagas as fardas dos soldados.

Documento 71

Timóteo Correa de Góis relata a Sua Majestade que saem da Fazenda Real os duzentos e noventa e cinco mil réis que faltam para os quatrocentos que Sua Majestade foi servido mandar pagar ao ouvidor geral desta comarca.

Documento 72

Timóteo Correa de Góis informa a Sua Majestade que os Padres da Companhia de Jesus perderam a causa do porto de Cubatão, de cuja sentença haviam apelado. Solicita informação de como proceder ao arremate pela Fazenda Real.

\section{Documento 73}

Timóteo Correa de Góis informa a Sua Majestade que, ao porto desta vila, chegou um navio francês com negros, marfim, ferro e cera bruta. Como se levaria tempo considerável para remetê-lo ao governador do Rio de Janeiro, venderam-se os negros. Descontadas as despesas, ficaram nove contos e setecentos mil réis.

\section{Documento 74}

Um crioulo, escravo de Frei José de Santa Brígida, do convento de Santo Antônio, foi repreendido por Antônio Freire Agostinho, que o mandou recolher-se, pois andava na rua fora de horas. Como 
respondeu que iria quando quisesse, aplicou-lhe Antônio Freire Agostinho umas vergastadas. No domingo, os padres pegaram Antônio Freire Agostinho, levaram-no à portaria do convento, onde estavam mais seis religiosos, tiraram-lhe a espada; na sala do capítulo, fizeram-no ajoelhar-se à força e deram-lhe, por três vezes, disciplinas que deixaram vergões. O juiz de fora abriu o termo de assentada em que foram ouvidas nove testemunhas.

\section{Documento 75}

O juiz de fora da vila de Santos, Matias da Silva, representou a Sua Majestade contra as insolências dos frades do convento de Santo Antônio para com o escrivão, Antônio Freire Agostinho. 


\section{Bibliografia}


ACIOLI, Vera Lúcia Costa. A escrita no Brasil colônia: um guia para leitura de manuscritos. Recife: Fundação Joaquim Nabuco, Ed. Massangana, 1994.

ALMEIDA, Antônio Paulino de. "Deterioração da escrita e leitura paleográfica", Boletim do Departamento do Arquivo. V. 10, fev., São Paulo,1953.

ARRUDA, José Jobson de Andrade (Coord.). Documentos manuscritos avulsos da Capitania de São Paulo (1644-1830): catálogo 1. Bauru, São Paulo: Edusc, Fapesp, Imesp, 2000.

AZEVEDO FILHO, L. A. Iniciação em Crítica Textual. Rio de Janeiro, São Paulo, Presença, Edusp, 1987.

BELLOTTO, Heloísa Liberalli. "Glossário das espécies documentais". In: ARRUDA, José Jobson de Andrade (Coord.) BELLOTTO, Heloísa Liberalli e REIS, Gilson Sérgio Matos (org.) Documentos manuscritos avulsos da Capitania de São Paulo (1644-1830): Catálogo 1. Bauru, EDUSC, 2000.

BERWANGER, Ana Regina, LEAL, João Eurípedes Franklin. Noções de paleografia e diplomática. Santa Maria: UFSM, Centro de Ciências Sociais e Humanas, 1991.

BISCHOFF, Bernhard. Latin paleography: antiquity and the middle ages. Cambridge: Cambridge University Press, 1997.

CAMBRAIA, César Nardelli, CUNHA, Antônio Gerado da, MEGALE, Heitor. A Carta de Pero Vaz de Caminha. Série Diachronica, 1, São Paulo, Humanitas, 1999.

CAMBRAIA, César Nardelli, MIRANDA, José Américo. Crítica Textual: reflexões e práticas. Belo Horizonte, Núcleo de estudos de Crítica Textual, Faculdade de Latras da UFMG, 2004.

CAMBRAIA, César Nardelli. Introdução à Crítica Textual. São Paulo, Martins Fontes, 2005.

CARLO, Agustín Millares. Paleografía española: ensayo de una historia de la escritura en España desde el siglo VIII al XVII. Barcelona, Buenos Aires: Labor, 1929.

COELHO, Maria Helena da Cruz, SANTOS, Maria José Azevedo, GOMES, Saul Antonio, MORUJÃO, Maria do Rosário. Estudos de 
diplomática portuguesa. Coimbra, Edições Colibri, Faculdade de Letras da Universidade de Coimbra, 2001.

CONTRERAS, Luis Núñez. Manual de paleografía: fundamentos e historia de la escritura latina hasta el siglo VIII. Madrid: Editorial Cátedra, 1994.

COSTA, Avelino de Jesus da. Normas gerais de transcrição e publicação de documentos e textos medievais e modernos. 3. ed. muito melhorada. Coimbra: Faculdade de Letras da Universidade de Coimbra; Instituto de Paleografia e Diplomática, 1993.

COSTA, Pe. Avelino Jesus da Álbum de paleografia e diplomática portuguesa. Coimbra, Universidade de Coimbra, 1976.

DIAS, João José Alves; OLIVEIRA MARQUES, Alexandre Herculano de; RODRIGUES, Teresa F. Álbum de Paleografia. Lisboa, Editorial Estampa, 1987.

DAIN, Alphonse. "Il problema della copia", in: STUSSI, Alfredo. (a cura di) La Critica del texto. Bologna, Il Molino. 1985.

DONATO, Ernani. A palavra escrita e sua história, São Paulo, Melhoramentos, 1951.

FACHIN, Phablo Marchis. Descaminhos e dificuldades: leitura de manuscritos do século XVIII. Goiânia, Fapesp, Trilhas Urbanas, 2008.

FERREIRA, Tito Lívio. "A paleografia e as suas dificuldades", Boletim do Departamento de Arquivo do Estado de São Paulo. v. 10, fev., São Paulo, 1953.

FIGUEIREDO, Manuel de Andrade de. Nova escola para aprender a ler, escrever, e contar. Lisboa Occidental: Officina de Bernardo da Costa Carvalho, [s.d.].

FLEXOR, Maria Helena Ochi. "Inventários e testamentos como fontes primárias de pesquisa", Boletim Histórico e Informativo do Arquivo do Estado de São Paulo. Vol. 3, n. 2, pg. 53-56, abr. - jun., São Paulo, 1982.

FLEXOR, Maria Helena Ochi. Abreviaturas: manuscritos dos séculos XVI ao XIX. 2 e., São Paulo, UNESP, Arquivo do Estado de São Paulo,1991. 
FRANÇA, Jean Marcel Carvalho. A São Paulo dos celerados. Trópico - Idéias de norte a sul, São Paulo, , v. 1, 22 jan. 2004.

GARCÍA, Elisa Ruiz. La escritura humanística y los tipos gráficos derivados. In: TERRERO, Ángel Riesco (ed.), Introducción a la paleografía y la diplomática general. Madrid: Editorial Síntesis, 2000, p. 149-176.

HIGOUNET, Charles. História concisa da escrita. São Paulo: Parábola Editorial, 2003.

HOUAISS, Antônio. Elementos de Bibliologia. V. 2, Rio de Janeiro, MEC, INL, 1967.

LEMOS, Carlos A. C. Organização urbana e arquitetura em São Paulo dos tempo coloniais, in: PRADO, Antonio Arnoni (et alii) História da Cidade de São Paulo: A cidade colonial 1554-1822. V. 1, p. 145-177, São Paulo, Paz e Terra, 2004.

LIMA, Yêdda Dias. Paleografia. Apostila do curso sobre paleografia. São Paulo: IEB, Universidade de São Paulo, 2006.

MAIA, Clarinda de Azevedo. História do galego-português: estado lingüístico da Galiza e do noroeste de Portugal desde o século XIII ao século XVI. Coimbra: Instituto Nacional de Investigação Científica, 1986.

MARCÍLIO, Maria Luíza. O crescimento demográfico e a evolução agrária paulista: 1700-1836. São Paulo: Hucitec, EDUSP, 2000.

MARIANA, Manuel Sánchez. Introducción al libro manuscrito. Madrid: Editorial Arco Libros, 1995.

MARQUES, Antônio Henriques de Oliveira. "Diplomática”, in: SERRÃO, Joel. Dicionário de História de Portugal e do Brasil. V. 2, p. 823828, Lisboa, Iniciativas Editoriais, 1971.

MARQUES, Antônio Henriques de Oliveira. "Paleografia", in: SERRÃO, Joel. Dicionário de História de Portugal e do Brasil. V. 5, p. $292-$ 298, Lisboa, Iniciativas Editoriais, 1971.

MARTÍNEZ, Tomás Marín. Paleografía y diplomática. Madrid, Universidad Nacional de Educación a Distancia, 2002.

MARTINS, Wilson A palavra escrita. São Paulo, Anhembi, 1957. 
MEGALE, Heitor. "Pesquisa Filológica: os trabalhos da tradição e os novos trabalhos em língua Portuguesa" in: Estudos Lingüísticos (Grupo de Estudos Ligüí́sticos do Estado de São Paulo). 27, p. 3-28, São José do Rio Preto, IBILCE, Unesp, 1998.

MEGALE, Heitor. "Filologia Bandeirante" in: Itinerários. 13, p. 11-31, Araraquara, Unesp, 1998.

MEGALE, Heitor. "Documentos brasileiros do século XVIII para estudo lingüístico" in: Estudos Lingüísticos (Grupo de Estudos Ligüísticos do Estado de São Paulo). 29, p. 309-314, Assis, Faculdade Unesp, 2000.

MEGALE, Heitor. (org.) Filologia Bandeirante; Estudos 1. 29, p. 309314, São Paulo, Humanitas, 2000.

MEGALE, Heitor e CAMBRAIA, César Nardelli. "Filologia Portuguesa no Brasil” in: DELTA Documentação de Estudos em Lingüística Teórica e Aplicada). 15, n. especial, p. 1-22, São Paulo, Educ, 2000

MEGAle, Heitor, TOLEDO NETO, Sílvio de Almeida, (Org.) Por minha letra e sinal: documentos do ouro do século XVII. São Paulo, Ateliê, FAPESP, 2005.

MEGALE, Heitor. TOLEDO NETO, Sílvio de Almeida, FERREIRA, ANDREA Hitos e SOUZA, Erica Cristina Camarotto de. "A leitura de manuscritos em Português: documentação do século XVII" in: MURAKAWA, Clotilde de Almeida Azevedo e GONÇALVES, Maria Filomena (Org.) Novas Contribuições para o estudo da história e da historiografia da língua portuguesa. P. 127-158, Araraquara, Unesp, 2007.

MENDES, Ubirajara. "Evolução das escritas: tipos caligráficos", Boletim do Departamento do Arquivo, v. 10, fev., São Paulo, 1953.

MENDES, Ubirajara. Noções de paleografia. São Paulo, Departamento do Arquivo do Estado de São Paulo, 1953.

MESGRAVIS, Laima. De bandeirante a fazendeiro in: PRADO, Antonio Arnoni (et alii) História da Cidade de São Paulo: A cidade colonial 1554-1822. V. 1, p. 115-143, São Paulo, Paz e Terra, 2004.

MONTEIRO, John M. Dos campo de Piratiniga ao Morro da Saudade in: 
PRADO, Antonio Arnoni (et alii) História da Cidade de São Paulo: A cidade colonial 1554-1822. V. 1, p. 21-67, São Paulo, Paz e Terra, 2004. MORAES, Rubens Borba de. Bibliografia brasileira do período colonial. São Paulo: Instituto de Estudos Brasileiros, Universidade de São Paulo, 1969.

MOURA, Américo de. "Paleografia: definição e generalidades", Boletim do Departamento do Arquivo. V. 10, fev., São Paulo, 1953.

NESBITT, Alexander. The history and technique of lettering. New York: Dover Publications, 1957.

NISHI, Elisabete Massami. Estudo grafemático de documento do século XIX, in: CD Estudos Lingüísticos, 30 ${ }^{\circ}$ Seminário do GEL. Marília, 2001

NISHI, Elisabete Massami. Edição de manuscritos brasileiros: estudo do $<\mathrm{h}>$ e das nasais, Carta de ordem de viagem do século XVIII, in: CD Estudos Lingüísticos, 30 ${ }^{\circ}$ Seminário do GEL. Marília, UNESP, 2002

RODRIGUES, José Honório. As fontes de História do Brasil na Europa. Rio de Janeiro, Imprensa Nacional, 1950.

SILVA NETO, Serafim da. Textos medievais portugueses e seus problemas. Rio de Janeiro: Casa de Rui Barbosa, 1956.

SILVEIRA, C. D. L. de A. Carta de ordem de viagem do século XVIII, em CD Estudos Lingüísticos, 30 ${ }^{\circ}$ Seminário do GEL. Marília, 2001

SILVEIRA, C. D. L. de A. O uso das sibilantes em textos militares dos séculos XVIII e XIX, em CD Estudos Lingüísticos, 30. Seminário do GEL, Marília, UNESP, 2002

SILVEIRA, C. D. L. de A. Documentação do Yguape, em Filologia e Lingüística Portuguesa. 5, p. 205-217, São Paulo, FFLCH da USP, 2003

SILVEIRA, C. D. L. de A. Edição e estudo de uma carta de 1825 , em comunicação no $32 .{ }^{\circ}$ Seminário do GEL, Taubaté, 2003 (inédito).

SOUSA JÚNIOR, Antônio. "Manuscritos do Brasil nos arquivos de Portugal", Revista do Instituto Histórico e Geográfico Militar do Brasil, n. 49, p 55-72, Rio de Janeiro, 1965. 
SPINA, Segismundo. Introdução à Edótica. 2 e., São Paulo, Edusp, Ars Poética, 1994.

TOLEDO NETO, S. de A. Constituição de corpus de documentação do século XVII, XVIII e XIX (PB-São Paulo), em DUARTE, M. E. e CALLOU, D. (ed.) Para a História do Português Brasileiro. V. IV, Rio de Janeiro, 20-02, p. 39-48.

TOLEDO NETO, S. de A. Uma incursão nas trilhas das bandeiras: edição semidiplomática do testamento de Bartolomeu da Cunha Gago, 1685, comunicação no 51. Seminário do GEL, Taubaté, Unitau, 2003 (inédito).

VALENTE, José Augusto Vaz. Álbum de paleografia portuguesa. São Paulo, USP, ECA, 1983.

VALENTE, José Augusto Vaz. De re paleografica. Marília, FAFI, 1983. 
Os documentos manuscritos, objeto deste livro, dão a conhecer a data e o lugar em que foram escritos, o nome de quem os elaborou e das pessoas envolvidas. Para o

pesquisador interessado, são informações que permitem um retrato, o mais fiel possível da língua escrita da época. Salta aos olhos um dos traços fundamentais do

conjunto de documentos publicados, a heterogeneidade, característica que se manifesta na convivência de punhos, possivelmente de muitas origens, com diversos graus de habilidade na escrita e detentores de variados hábitos de escrita. Além das características individuais de cada escriba, há que se considerar também as diferentes espécies documentais, públicas ou particulares, elaboradas com base em diferentes modelos e em diferentes contextos. A partir desses fatores, evidencia-se, nos textos

que compõem esse corpus, um vasto panorama para os estudos filológicos e linguísticos. Com a cautela exigida, é possível buscarem-se indícios de retenção linguística em traços presentes na variedade padrão ou não-padrão escrita da época, e

hoje encontrados, no Brasil, com maior frequência na fala coloquial, mais especificamente de idosos, com baixa escolaridade, criados e radicados em ambiente rural. Pode-se afirmar que o recorte documental reunido constitui- se em conjunto de escritos que pretende retratar, de forma ampla, o estado de língua do período, por meio de edição conservadora.

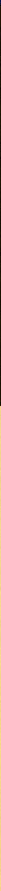

